\title{
Extension of shelf life of commercial opaque beer using flash pasteurisation process
}

\author{
Benias Nyamunda ${ }^{* 2}$, Ropafadzo Tshalibe ${ }^{1}$, Tecklah Usai ${ }^{1}$, Fortune Rwafa ${ }^{1}$ \\ ${ }^{1}$ Midlands State University, Department of Food Science, Private Bag 9055 Gweru, Zimbabwe. \\ ${ }^{2}$ Manicaland College of Applied Sciences, Department of Chemical and Processing Engineering, \\ Fernhill Campus, Mutare, Zimbabwe. \\ Corresponding Author email: nyamundabegmail.com
}

\begin{abstract}
The effects of flash pasteurisation of wort after second conversion stage were investigated with the intention of extending the shelf life of opaque beer from current $120 \mathrm{~h}$. The extension of shelf life was determined by following the biochemical, physico-chemical and the sensory profile of the variants up to the point total acidity goes beyond the threshold of $0.5 \% \mathrm{v} / \mathrm{v}$. The samples were subjected to wort flash pasteurisation for 120 seconds. Flash pasteurisation extended the shelf life of the beer from $120 \mathrm{~h}$ to $168 \mathrm{~h}$. The physical, chemical and sensory attributes of the beer remained the same.
\end{abstract}

Keywords: flash pasteurisation, malt, mashing, shelf life, opaque beer

\section{Introduction}

Brewing of traditional opaque beer is a common practice among African societies. The brewing processes involve the blending of sorghum malt and meal, barley malt and straight run maize grits. Extraction and breakdown of carbohydrates from these raw materials to make a sugar solution and subsequent fermentation with yeast produce ethanol and carbon dioxide [1]. Brewing of opaque beer has been commercialised, currently the opaque beer industry is a well established and expanding [2]. In Zimbabwe there are at least 20 opaque beer breweries that produce over 420 million litres of the beer annually [1], [3].

Sorghum malt which is added during second conversion (mashing) stage in the brewing process of opaque beer has a high microbial load and is the major source of contamination [4], 5]. There is no further heat treatment or any other sterilisation process carried out after the second conversion that inhibits or eliminates the growth of the bacteria. Opaque beer is therefore sold as a microbiologically active and live product which is prone to spoilage as beneficial acid producing bacteria continue to grow even after acceptable levels of total acids have been attained [6], [7], [8], [9]. The short shelf life of opaque beer (120 hours) remains a big problem to the profitability of brewing opaque beer.

Efforts have been made aiming at improving the shelf life of opaque beer. These include removing the second malt conversion stage, beer refrigeration and carbonation and substituting sorghum malt with commercial amylase enzyme, Alphalase [1], [10], [11]. However the high cost and infrastructural requirements of these preservation techniques greatly restrict their application in the extension of shelf life of opaque beer.

The focus of this study therefore is to extend the shelf life of opaque beer brewed from a local commercial company (Pungwe Breweries, Mutare, Zimbabwe). Shelf life extension would be achieved through flash pasteurisation of wort after second conversion stage in the brewing process to reduce the load of acid producing bacteria in wort. The pasteurisation process is done prior to the second conversion stage. An additional pasteurisation process will not have significant additional costs to the entire brewing process. Pasteurisation is a heat treatment process applied to kill pathogenic bacteria and to significantly reduce the spoilage microbial load [12], 13]. Appropriate combination of temperature and time will minimise changes in the sensory (flavour, colour) and quality of the beer. The effects of flash pasteurisation on head retention, settling time, viscosity, $\mathrm{pH}$, total acids, alcohol content of the opaque beer were investigated.

ACRID 2017, June 20-21, Victoria Falls, Zimbabwe

Copyright (C) 2017

DOI 10.4108/eai.20-6-2017.2270763 


\section{Methodology}

\subsection{Materials and the Brewing Process}

Sorghum and barley malt were procured from Aspindale maltings in Harare, Zimbabwe, Maize was bought from the Zimbabwe grain marketing board. Yeast was obtained from Anchor Yeast Gweru, Zimbabwe. Lactic acid was imported from Hanan Jindan lactic acid Technology Company in USA. Deionised water was used in all preparation of mixtures. The ingredients were mixed in appropriate amounts and underwent brewing multi-purpose vessel as outlined in Figure 1.

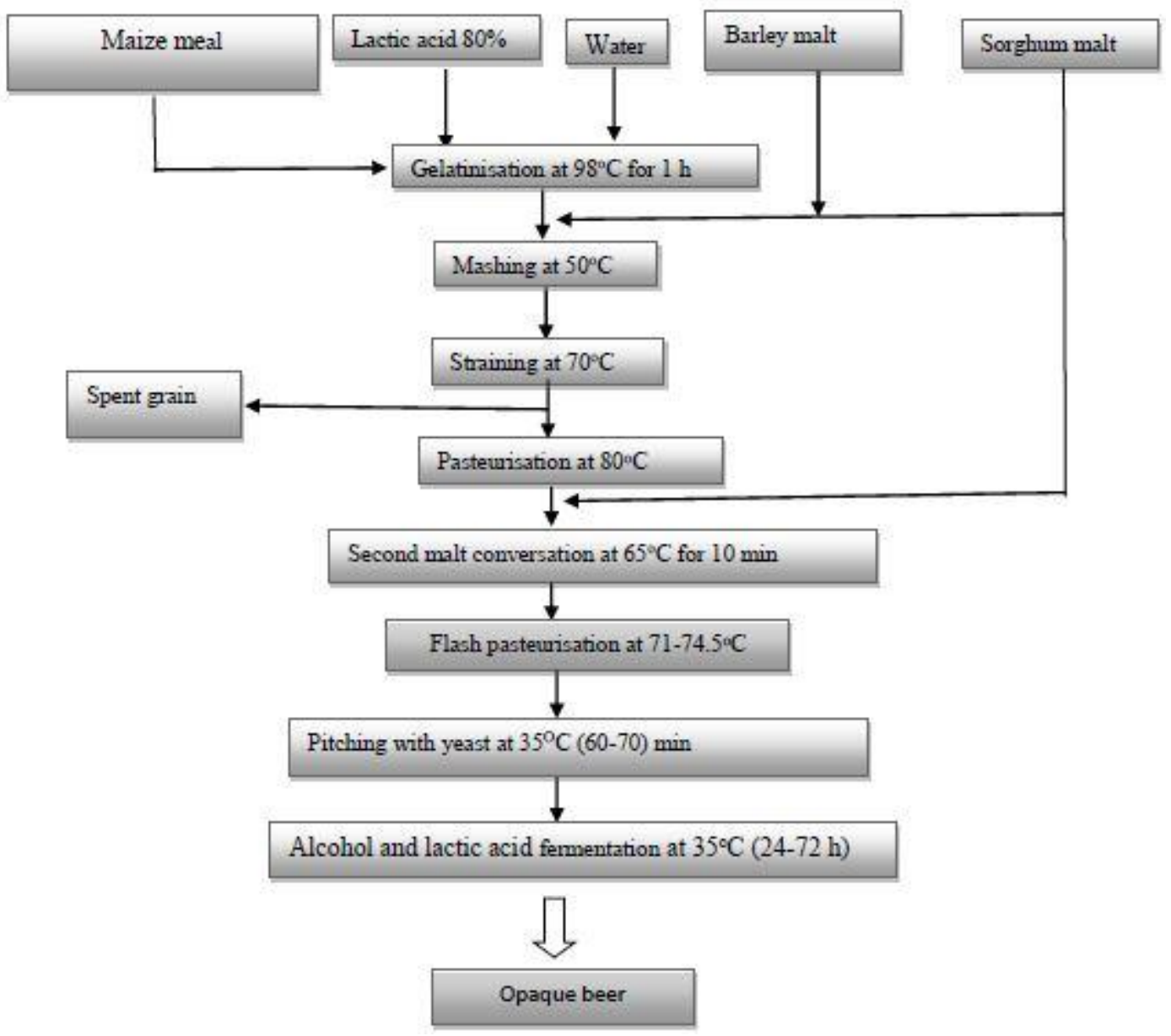

Fig. 1. Outline of the opaque beer brewing process. 


\subsection{Flash Pasteurisation}

After second conversation (mashing), $200 \mathrm{~L}$ of wort was collected from the multi-purpose vessel and transferred into $20 \mathrm{~L}$ containers. All experiments were done in duplicates and the results presented as mean values.

Two of the $20 \mathrm{~L}$ wort samples were not flash pasteurised and were used as control (NFP). The other wort samples (FP) were flash pasteurised at $71.5-74^{\circ} \mathrm{C}$ for different duration (30, $60,120,240 \mathrm{~s})$. After flash pasteurisation the samples and control underwent pitching and fermentation (Figure 1). The biochemical, physico-chemical, microbiological, organoleptic profiles tests were then carried out on the brewed samples.

\subsection{Determination of Viscosity}

Viscosity was measured using the Brookfield Synchro-Lectric viscometer LVT BF35 model. Viscosity was measured at $25^{\circ} \mathrm{C}$.

\subsection{Alcohol Content}

A thoroughly mixed beer sample $(100 \mathrm{ml})$ was transferred into a distillation flask containing $100 \mathrm{ml}$ deionised water. Distillation was done until $100 \mathrm{ml}$ of distillate were collected. The distillate was cooled to $20^{\circ} \mathrm{C}$ and its specific gravity (SG) determined as the ration of weight of distillate to weight of distilled water. The alcohol content was derived from the corresponding specific gravity conversion tables.

\subsection{Foam-Head and Settling}

Opaque beer sample $(300 \mathrm{ml})$ was poured into a $1000 \mathrm{ml}$ measuring cylinder and foam height was measured after allowing the beer to stand for 30 minutes. Settling height was also measured after allowing the beer to stand for 5 minutes. Percentage foam was calculated by determining the volume of foam on top of the liquid as a percentage of total liquid excluding foam. Percentage settling was calculated by determining the volume of clear liquid on top of the solids as a percentage of total liquid volume.

\subsection{Total Acidity}

Each beer sample $(100 \mathrm{ml})$ was filtered through a no. 1 Whatman filter paper after which 10 $\mathrm{ml}$ of the filtrate was titrated against $0.1 \mathrm{M} \mathrm{NaOH}$ using phenolphthalein indicator until a permanent pink colour persisted for 30 seconds. The titration was done in triplicate for each sample.

\section{$2.7 \mathrm{pH}$}

The $\mathrm{pH}$ of the opaque beer was measured using a Jenway $3520 \mathrm{pH}$ meter at room temperature. Before $\mathrm{pH}$ measurement, carbon dioxide from the beer samples $(100 \mathrm{~mL})$ was initially dissipated by stirring with a glass rod for 5 minutes.

\subsection{Total Bacterial Count}

Determination of total bacteria count was done before pitching. It was done in all the beer samples and their successive dilutions. The working area was first cleaned and sanitized using $75 \%$ ethanol. About $20 \mathrm{ml}$ of plate count agar was poured into each Petri dish. Using a sterile pipette, $1 \mathrm{ml}$ of beer samples was transferred to the Petri dish. The procedure was repeated with further dilutions using a fresh sterile pipette for each dilution. The inoculum and the medium were thoroughly and uniformly mixed by alternate rotation and back and forth motion on a shaker. Sterility plates were prepared by pouring $20 \mathrm{ml}$ of the medium into empty Petri dishes. The mixture was allowed to solidify, with Petri dishes standing on a cool horizontal surface. After complete solidification; the prepared Petri dishes were inverted and incubated (promptly) in an incubator at $37^{\circ} \mathrm{C}$ for $48 \mathrm{~h}$. After the specified incubation period, the colonies on each plate were determined using a colony counter.

\subsection{Sensory Evaluation}

Sensory evaluation was done by ten trained panellists selected from the technical laboratory who were familiar with the product. All the brews were tested from $72 \mathrm{~h}$ shelf life until the 
beer samples were no longer palatable. The beer samples were coded and masked so as to minimise bias. The coded samples were served in transparent plastic cups together with biscuit and water to rinse their mouths between each sample. Sensory evaluation was done by use of organoleptic taste and preference test.

\section{Results and Discussion}

\subsection{Physico-Chemical Properties}

\subsubsection{Total Acidity and $\mathrm{pH}$}

The change in total acidity in opaque beer samples with time is shown in Figure 2. The flash pasteurised sample where denoted by duration of pasteurisation (FP30 means sample flash pasteurised for $30 \mathrm{~s}$ ). All flash pasteurised samples showed a lower total acidity compared to non flash pasteurised (NFP) samples at any given shelf life of the beer. The total acid in FP samples decreased with increasing time of flash pasteurisation. All FP samples except FP30 contained not more than $0.5 \%(\mathrm{v} / \mathrm{v})$ total acid up to a shelf life of 144 h. Only FP120 and FP240 contained total acidity below the threshold ( $0.5 \% \mathrm{v} / \mathrm{v})$ after $168 \mathrm{~h}$ ( 0.43 and $0.48 \%$ respectively). Flash pasteurisation retarded the rate of total acids accumulation resulting in prolonged beers shelf life. Flash pasteurisation reduced the population of bacteria producing acids. Longer holding times during flash pasteurisation ensured a greater number of deactivated bacteria.

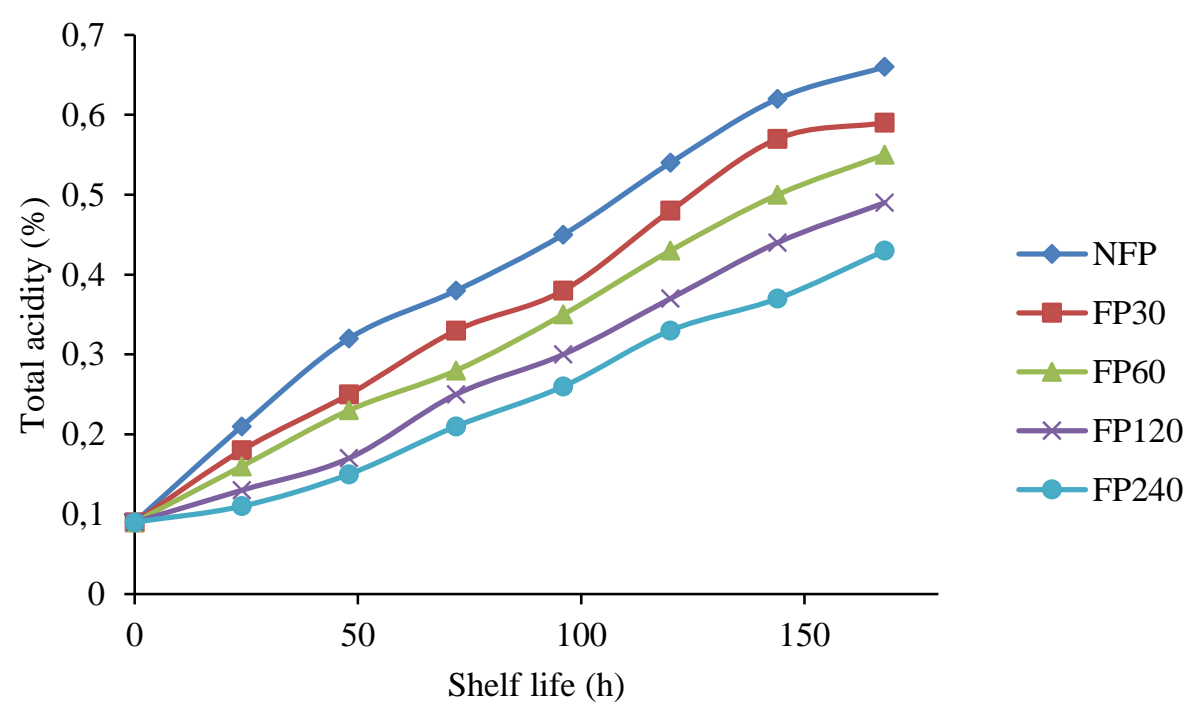

Fig. 2. Total acidity of opaque beer as a function of shelf life.

Figure 3 shows the effect of flash pasteurisation on the $\mathrm{pH}$ of opaque beer. NFP had the highest $\mathrm{pH}$ during the entire shelf life of the beer. A decrease in $\mathrm{pH}$ with time was observed in all samples due to increase in acid production by the bacteria. FP samples that were pasteurised for longer duration showed higher $\mathrm{pH}$ than short time pasteurised samples. Longer pasteurisation times resulted in a greater population of deactivated or denatured bacteria. 


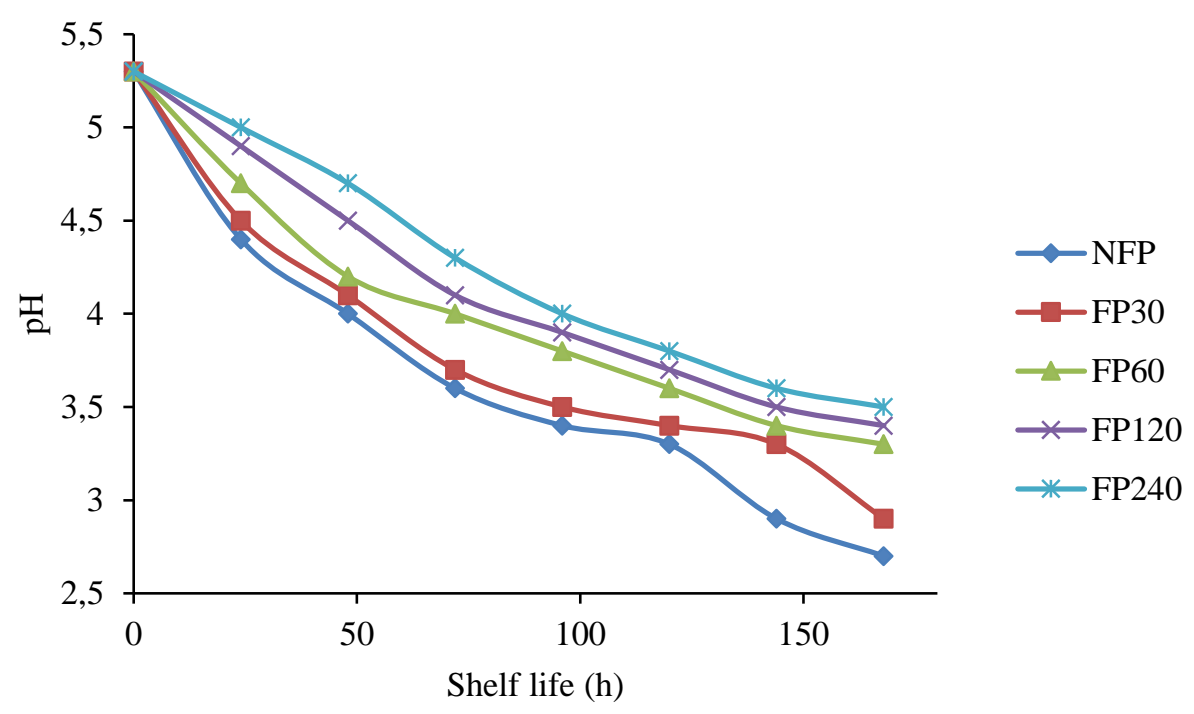

Fig. 3. $\mathrm{pH}$ changes during the shelf life of opaque beer

\subsubsection{Alcohol Content}

The changes in alcohol (ethanol) content of the beer samples with time are shown in Figure 4. Flash pasteurisation of wort after second conversation had no effect on the alcohol fermentation profile. According to Gadaga et al [14], the amount of fermentable sugars and other essential nutrients for fermentation are not affected by flash pasteurisation. The quantities of fermentable sugars and essential nutrients at beginning of the fermentation were essentially the same in all beer samples hence their pattern of fermentation was identical. There was an increase in alcohol content with time since the yeast bacteria responsible for fermentation were producing more ethanol. A decline in percentage of alcohol level beyond $144 \mathrm{~h}$ in all beer samples was a result of oxidation of ethanol to acetic acid.

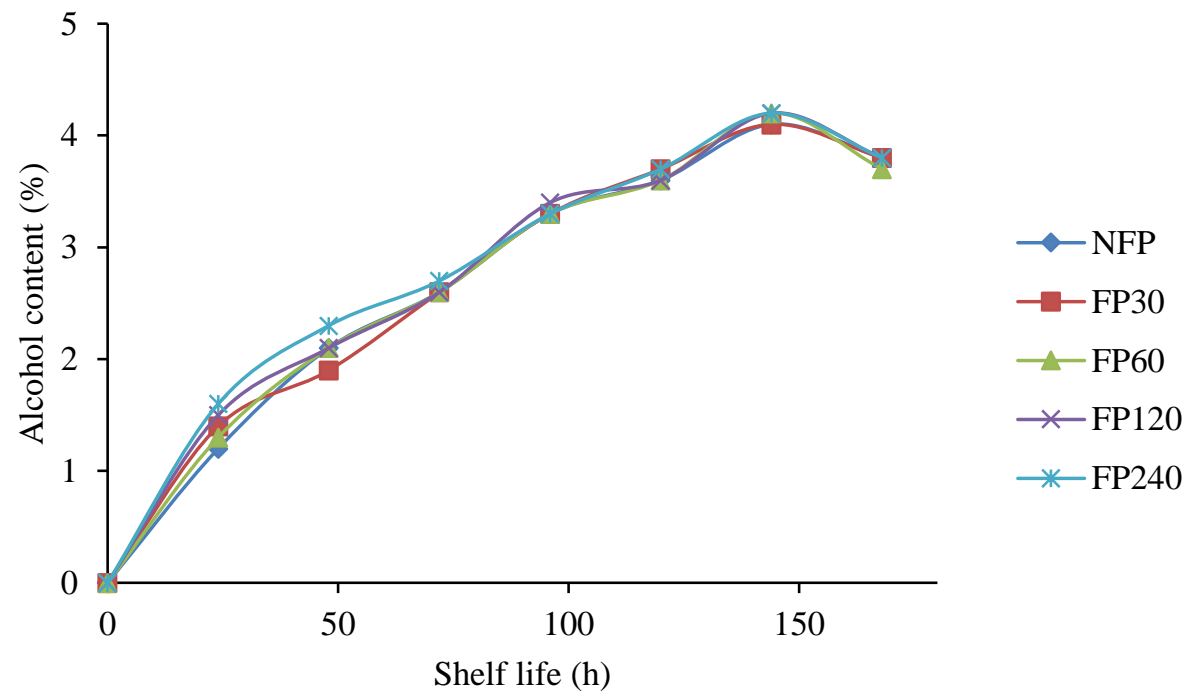

Fig. 4. Changes in ethanol content during shelf life of the opaque beer 


\subsubsection{Viscosity}

Viscosity is an important parameter since it affects the rate of settling in beer and is important for mouth feel. The viscosity of all beer samples for the first $48 \mathrm{~h}$ was $80 \mathrm{gcm}^{-1} \mathrm{~s}^{-}$ ${ }^{1}$. This constant value indicated that flash pasteurisation has no effect on beer viscosity. Above $48 \mathrm{~h}$, the viscosity of all beer samples decreased to $70 \mathrm{gcm}^{-1} \mathrm{~s}^{-1}$. According to Benhura and Chingombe [15], viscosity of opaque beer is affected by the extend of conversion of starch into fermentable sugars. Under conversion give rise to a viscous product while over conversion produces a less viscous beer which settles more easily.

\subsubsection{Head retention and settling}

The nature of foam that a beer develops is one of the parameters that consumers consider when judging the quality of beer. When considering beer foam it is necessary to look at the head formation, which is the ability of beer to form a head when poured as well as head retention, which is the ability of beer to retain a head once it has formed, after dispense. It is crucial to have adequate head formation in order to ensure sufficient foam remains during the consumption of beer. A satisfactory head is one that persists for more than 90 seconds [16]. The head retention of all beer samples were more or less the same (130 s) during the life time of $168 \mathrm{~h}$ and no settling was observed in all beer samples suggesting that flash pasteurisation does not affect these two parameters.

\subsection{Bacterial count}

The mean total bacterial count of the beer samples is shown in Table 1. NFP sample had the least bacteria population before adding second conversion malt. Addition of second malt brings more bacteria to the opaque beer as evidenced by an increase in bacterial count. After adding the second malt, NFP had the largest bacteria count while NFP240 exhibited the least count. Flash pasteurised samples showed lower total bacteria count. FP samples subjected to longer pasteurisation times exhibited lower total bacterial count. Flash pasteurisation destroyed some of the bacteria. 
Table 1. Mean total bacterial counts of opaque beer

\begin{tabular}{ll}
\hline Sample & Total bacterial count (c.f.u/ml) \\
\hline NFP after initial pasteurisation & $3.84 \times 10^{4}$ \\
NFP after adding second conversion malt & $2.45 \times 10^{10}$ \\
FP30 after adding second conversion malt & $9.3 \times 10^{6}$ \\
FP60 after adding second conversion malt & $4.5 \times 10^{6}$ \\
FP120 after adding second conversion malt & $4.4 \times 10^{5}$ \\
FP240 after adding second conversion malt & $2.0 \times 10^{5}$ \\
\hline
\end{tabular}

\subsection{Sensory Evaluation}

Table 2 summarises some of the sensory attributes of the beer samples. The thickness, bite, bubble size, colour, sweetness and texture of all flash pasteurised the beer samples conformed to the ideal beer characteristics for the maximum shelf life of $168 \mathrm{~h}$. All the beer samples were described as resembling the original opaque beer brand with characteristic reddish-brown colour. NFP showed maximum lacing (5) after $120 \mathrm{~h}$ while pasteurised samples deviated from ideal lacing (4) after $168 \mathrm{~h}$. All samples were odourless for $168 \mathrm{~h}$ except for FP240 that had an odour after $168 \mathrm{~h}$. NFP was slimy after $120 \mathrm{~h}$. PF30 and PF60 showed no sliminess for $168 \mathrm{~h}$. FP120 and FP240 exhibited sliminess at 144 and $120 \mathrm{~h}$ respectively. Mouth feel of all beer samples was ideal with the exception of FP240 which deviated after $168 \mathrm{~h}$. Prolonging flash pasteurisation time had deteriorative effects on the organoleptic taste of the beer. After a shelf life of 168 h, FP240 started to develop odours and off-flavours and became slimy suggesting that long pasteurisation time adversely affected the beer's sensory qualities.

Table 2. Organoleptic taste scores for the beer samples

\begin{tabular}{|c|c|c|c|c|c|c|c|c|c|c|c|c|c|c|c|c|}
\hline \multirow[t]{3}{*}{ Parameter } & \multirow[t]{3}{*}{ Ideal } & \multicolumn{5}{|c|}{$120 \mathrm{~h}$} & \multicolumn{5}{|c|}{$144 \mathrm{~h}$} & \multicolumn{5}{|c|}{$168 \mathrm{~h}$} \\
\hline & & $N$ & FP & FP & FP & FP & $\mathrm{N}$ & $\mathrm{FP}$ & $\mathrm{FP}$ & FP & FP & $\mathrm{N}$ & FP & FP & $\mathrm{FP}$ & FP \\
\hline & & FP & 30 & 60 & 120 & 240 & FP & 30 & 60 & 120 & 240 & FP & 30 & 60 & 120 & 240 \\
\hline Bite & 3 & 3 & 3 & 3 & 2 & 1 & 4 & 3 & 3 & 2 & 1 & 5 & 4 & 3 & 3 & 2 \\
\hline Thickness & 3 & 3 & 3 & 3 & 3 & 3 & 3 & 3 & 3 & 3 & 3 & 3 & 3 & 3 & 3 & 3 \\
\hline Bubble size & 3 & 2 & 3 & 3 & 3 & 3 & 2 & 2 & 3 & 3 & 3 & 1 & 2 & 2 & 2 & 3 \\
\hline Lacing & 4 & 4 & 4 & 4 & 4 & 4 & 5 & 4 & 4 & 4 & 4 & 5 & 5 & 5 & 5 & 4 \\
\hline Colour & 3 & 3 & 3 & 3 & 3 & 3 & 3 & 3 & 3 & 3 & 3 & 3 & 3 & 3 & 3 & 3 \\
\hline Mouth Feel & 4 & 4 & 4 & 4 & 4 & 5 & 4 & 4 & 4 & 4 & 5 & 4 & 4 & 4 & 4 & 5 \\
\hline Sour & 2 & 2 & 2 & 2 & 1 & 1 & 3 & 3 & 2 & 1 & 1 & 4 & 4 & 2 & 2 & 2 \\
\hline Sweetness & 1 & 1 & 1 & 1 & 1 & 1 & 1 & 1 & 1 & 1 & 1 & 1 & 1 & 1 & 1 & 1 \\
\hline Sliminess & 0 & 0 & 0 & 0 & 0 & 1 & 0 & 0 & 0 & 1 & 2 & 0 & 0 & 0 & 1 & 3 \\
\hline Texture & 2 & 2 & 2 & 2 & 2 & 2 & 2 & 2 & 2 & 2 & 2 & 2 & 2 & 2 & 2 & 2 \\
\hline Odour & 0 & 0 & 0 & 0 & 0 & 0 & 0 & 0 & 0 & 0 & 0 & 0 & 0 & 0 & 0 & 1 \\
\hline
\end{tabular}

\subsection{Preference Test}

Figure 5 shows the preference test scores of the beer samples after $168 \mathrm{~h}$. Preference test at $168 \mathrm{~h}$ indicated that most panellists preferred FP120 (35\%). Preference percentage of the control was $3 \%$ while the beer sample that was pasteurised for $30 \mathrm{~seconds}$ had $9 \%$, the beer sample that was flash pasteurised for 60 seconds had $24 \%$ and the beer sample that was flash pasteurised for 240 seconds had $29 \%$. 


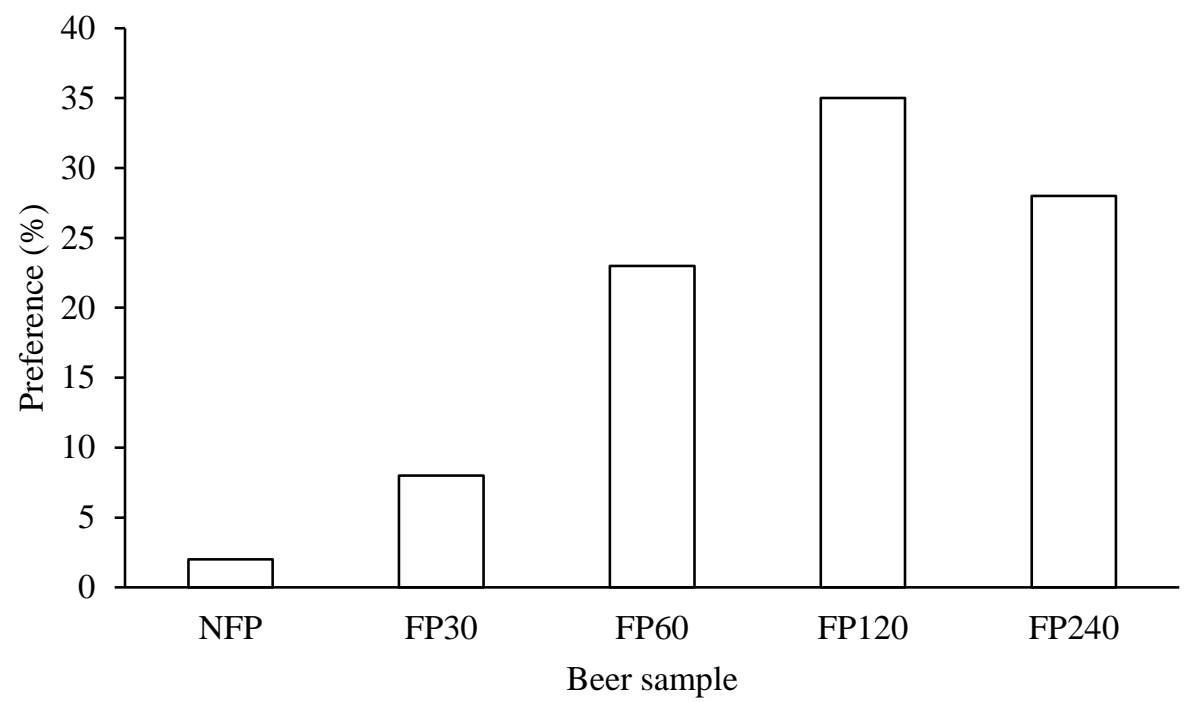

Fig. 5. Preference percentage of beer samples at $168 \mathrm{~h}$ shelf life

\section{Conclusion}

The study has shown that flash pasteurisation extended shelf life of beer from the current 120 to $168 \mathrm{~h}$. The duration of flash pasteurisation had a bearing on the number of bacteria destroyed. Increasing flash pasteurisation time reduced the total bacterial count subsequently resulting in reduction in the quantities of acids produced during fermentation. Flash pasteurising wort delayed the time taken to reach the unacceptable total acids threshold of $0.5 \% \mathrm{v} / \mathrm{v}$. Flash pasteurising wort for 240 seconds resulted in beer samples developing off-flavours and odours in shorter shelf life (less $168 \mathrm{~h}$ ) compared to pasteurising in 120 seconds which brings minimal changes to the product's organoleptic taste consistency. Preference tests showed that FP120 beer samples were preferred most.

Flash pasteurisation has demonstrated to be a viable strategy in extending the shelf life of opaque beer. Further studies to optimise the process and determine consumer acceptability of the product on the market need to be carried out.

\section{Acknowledgements}

Authors are grateful to Pungwe breweries for providing research facilities.

\section{References}

1. Kutyauripo, J., Parawira, W., Tinofa, S., Kudita, I., Ndengu, C.: Investigation of Shelf-Life Extension of Sorghum Beer (Chibuku) by Removing the Second Conversion of Malt. Int. J. Food Microbiol. 129 (30), 271-276 (2009).

2. Clark, V.: Cheers to a Burgeoning Beer Market: African Focus. South African Food Rev. 39(9), 38-40 (2012).

3. Parawira, W., Kudita, I., Nyandoroh, M.G., Zvauya, R.: A Study of Industrial Anaerobic Treatment of Opaque Beer Brewery Wastewater in a Tropical Climate Using a Full-Scale UASB Reactor Seeded with Activated Sludge. Process Biochem. 40(2), 593-599 (2005).

4. Matumba, L., Monjerezi, M., Khonga, E.B., Lakudzala, D.D.: Aflatoxins in Sorghum, Sorghum Malt and Traditional Opaque Beer in Southern Malawi. Food Control. 22(2), 262-268 (2011).

5. Perez-Carrillo, V., Serna-Saldivar, S.O., Chuck-Hernandez, C., Cortes-Callejas, M.L.: Addition of Protease During Starch Liquefaction Affects Free Amino Nitrogen, Fusel Alcohols and Ethanol Production of Fermented Maize and Whole and Decorticated Sorghum Mashes. Biochem. Eng. J. 67, 1-9 (2012). 
6. Todorov, S.D., Dicks, L.M.T.: Screening of Lactic-Acid Bacteria from South African Barley Beer for the Production of Bacteriocin-Like Compounds. Folia Microbiol. 49(4), 406-410 (2004).

7. Kayodé, A.P.P., Deh, D.C., Baba-Moussa, L., Kotchoni, S,O., Hounhouigan J.D.: Stabilization and Preservation of Probiotic Properties of the Traditional Starter of African Opaque Sorghum Beers. Afr. J. Biotechnol. 11(30), 7725-7730 (2012).

8. Rathore, S., Salmerón, I., Pandiella, S.S.: Production of Potentially Probiotic Beverages Using Single and Mixed Cereal Substrates Fermented with Lactic Acid Bacteria Cultures. Food Microb. 30(1), 239-244 (2012).

9. Sharpton, D.A., and Gibbs, B.M.: Identification Methods for Microbiologists Part B. The Society for Applied Bacteriology. Academic, London (2006).

10. Taylor, J.R.N., Schober, T.J., Bean, S.R.: Novel Food and Non-Food Uses for Sorghum and Millets. J. Cereal Sci. 44(3), 252-271 (2006).

11. Casiraghi, C., Robertson, J., Ferrari, A.C.: Diamond-Like Carbon for Data and Beer Storage, Mater. Today. 10(1-2), 44-53 (2007).

12. Dagan, G.F., Balaban, M.O.: Pasteurization of Beer by a Continuous Dense-Phase $\mathrm{CO}_{2}$ System. J. of Food Sci. 71( 3), E164-E169 (2006).

13. Arthur, H., Joubert, E., De Beer, D., Malherbe, C.J.: Phenylethanoid Glycosides as Major Antioxidants in Lippia Multiflora Herbal Infusion and their Stability During Steam Pasteurisation of Plant Material. Food Chem. 27(2), 581-588 (2011).

14. Gadaga, H.T., Mutukumira, A.N., Narvhus, J.A., Feresu, S.B.: A Review of Traditional Fermented Food Beverages of Zimbabwe. Int. J. Food Microbiol. 53(1), 1-11 (1999).

15. Benhura, M.A., Chingombe, A.: Traditional Brewing Methods of Zimbabwe. Zimbabwe Sci. News. 23, 69-70 (1989).

16. O'Rourke, T.: The Function of Enzymes in Brewing. The Brewer Int. 2(7), 11-20 (2002. 